Original Research Article

\title{
A meta-analysis of analgesic efficacy of opioids in the treatment of neuropathic pain
}

\author{
Preethi A., Kulandaiammal M.*
}

Department of Pharmacology, Government Stanley Medical College, Chennai, Tamil Nadu, India

Received: 02 February 2019 Accepted: 08 March 2019

*Correspondence to:

Dr. Kulandaiammal M,

Email:

drkulandpharma@gmail.com`

Copyright: () the author(s), publisher and licensee Medip Academy. This is an openaccess article distributed under the terms of the Creative Commons Attribution NonCommercial License, which permits unrestricted noncommercial use, distribution, and reproduction in any medium, provided the original work is properly cited.

\begin{abstract}
Background: Neuropathic pain is the most common form of chronic pain often associated with impaired quality of life due to its poor management. Tricyclic antidepressants, serotonin and norepinephrine reuptake inhibitors and calcium channel alpha 2 ligand agonist are preferred as first line therapy for neuropathic pain. Lignocaine patches and transdermal patches of capsaicin are used as second line agents. Moderate efficacy opioids like tramadol and strong opioids are recommended as second line and third line therapy for neuropathic pain respectively. Previous meta-analysis and systematic review shows inconsistent data and lacks reliability in getting conclusive results in opioids use in neuropathic pain. So, author conducted a meta-analysis to reanalyse the analgesic efficacy of opioid agonist for the treatment of neuropathic pain.

Methods: Author searched Oxford pain relief data base, Google web, Embase, Medline and Cochrane library from February 2001 to November 2017 for articles related to analgesic efficacy of opioid agonist in neuropathic pain based on author's selection criteria. Reference list of reviews were retrieved using Prisma Algorithm and analysed using REVIEW MANAGER 5 software.

Results: Among 1108 publications searched, only 5 trials met the inclusion criteria. Primary outcome measure was proportion of participants reporting $50 \%$ of pain relief or better. In five trials, 305 patients treated with opioids and placebo/standard treatment for neuropathic pain, the number per treatment group

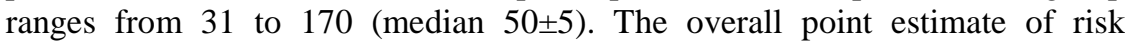
difference was 0.17 (95\% CI 0.02 to $0.33, \mathrm{P}=0.026)$ translating to number needed to treat (Benefit) of 5.9 (3.0 to 50.0).

Conclusions: In this meta-analysis, opioid agonist efficacy trials shown consistent analgesic efficacy and benefit over placebo/standard treatment in reducing neuropathic pain.
\end{abstract}

Keywords: Analgesia, Meta-analysis, Neuropathic pain, Opioid agonist

\section{INTRODUCTION}

International association for the study of pain define pain as "an unpleasant sensory and emotional experience associated with actual or potential tissue damage or described in terms of such damage "one in five people of all ages have estimated to be suffering from moderate to severe pain, one third of individuals of working age who have chronic pain have lost the ability to perform wage earning or other work. ${ }^{1,2}$ Chronic pain is defined as "pain without apparent biological value that has persisted beyond the normal tissue healing time usually taken to be 3 months. ${ }^{3}$ Access to timely and appropriate treatment for chronic pain is an international problem. Poor access to health care can lead to progression of disease which further decreases the quality of life. ${ }^{4,5}$

Neuropathic pain is defined as "pain arising as a direct consequence of a lesion/disease affecting the somatosensory system". ${ }^{4,5}$ Neuropathic pain accounts for 7-8\% of total population diagnosed with pain. Many theories have been implicated for the pathophysiology of neuropathic 
pain recently. Chemical excitation of non-nociceptors, excitotoxicity, ectopic discharge of pain signals, deafferentation, central sensitization and antidromic neurogenic inflammation are the current postulates for neuropathic pain.

Neuropathic pain drug treatment updated guidelines from the International association for the study of pain recommends tricyclic antidepressant, serotonin and norepinephrine reuptake inhibitors like duloxetine and venlafaxine, calcium channel alpha 2 ligands agonist like gabapentin and pregabalin are the first line drugs for neuropathic pain. ${ }^{5-8}$ Lidocaine patches, $8 \%$ capsaicin patches and tramadol are given as second line therapy for neuropathic pain. strong opioids are recommended only as third line reserve for neuropathic pain. WHO pain ladder with pain management guidelines was initially developed for management of cancer pain but now worldwide consensus promoting their use for the medical management of all pain associated with serious illness including neuropathic pain. WHO pain ladder step 2 for moderate pain recommends moderate efficacy opioids like tramadol and in step 3 for severe pain, strong efficacy opioids (morphine, oxycodone) were recommended in neuropathic pain.

In neuropathic pain, controversy exist in giving opioid agonist about their efficacy and safety in long term use. ${ }^{9,10}$ Previous meta-analysis and systematic review shown in conclusive results and trials taken previously lacks homogeneity to show adequacy in efficacy results, so author decided to conduct a meta-analysis of efficacy trials done for opioid agonist from 2001 February to 2017 November to re-evaluate and analyse the analgesic efficacy of opioid agonist in the treatment of neuropathic pain.

\section{METHODS}

Author searched oxford pain relief data base, Google web, Embase, Medline and Cochrane library from 2001 February to 2017 November for articles related to analgesic efficacy of opioids in any language based on the selection criteria. Opioid agonist analgesic efficacy articles were filtered out in a systematic manner. ${ }^{11-14}$ Reference list of original articles which were considered reliable for analysis were retrieved using Prisma algorithm and those final lists of articles were compared and analysed for their demographic profile, drugs given, methodology used, and outcome evaluated for efficacy of opioids. ${ }^{11}$

Inclusion criteria were randomized control trials of efficacy of opioids compared with placebo/standard treatment in neuropathic pain. Original articles of opioid agonist published in indexed journal with reliable source of information were included in the study. ${ }^{15}$ Opioids given through oral, transdermal or intravenous route used to treat either central or peripheral neuropathic pain of any etiology were included. Pain intensity outcomes validated through visual analogue scale for any time duration were included. Non randomized trials or review articles of opioid agonist were excluded. Articles related to opioid agonist given in combination drugs or opioids given along with surgical procedure for pain relief were not included. opioid agonist which were administered epidurally or intrathecally for pain relief were excluded.

\section{Data extraction}

This study was commenced only after getting approval from Institutional Ethics committee, Government Stanley Medical College, Chennai, India. Two authors (p, k) independently collected the data using standardized protocol. Each set was crosschecked by another author. Information about details of neuropathic pain syndrome, study design and duration, sample size, treatment and controls, number randomized and analysed, number enrolled and completed the study, pain outcome and level of statistical significance was extracted recorded in the predefined standard proforma sheet. VAS score difference (0-100) before and after treatment for each treatment groups were noted. In case of any incomplete pain data, number of patients (pre/post drop outs), the missing values were computed by addition/subtraction of data in the same study.

\section{Outcome}

Effectiveness of opioid agonist treatment was assessed by pain relief. Primary outcome measure was proportion of participants reporting $50 \%$ of pain relief or better from baseline using Visual analogue scale (0-100).

\section{Statistical analysis}

All the data were entered in Microsoft Excel Worksheet version 2007. Using Cochrane Review Manager 5.0 software, relative risk was calculated with $95 \%$ confidence interval for this discrete event such as number of participants reporting $50 \%$ pain relief were analysed. Statistical consistency was verified through performing heterogeneity test (higher values mean higher heterogeneity) which were evaluated using Chi2 and I2 statistics. All analyses were calculated by means of conservative random effects model.

\section{RESULTS}

For this meta-analysis study, total of 1108 articles were searched in different web like oxford pain relief database, Google web, Medline, Embase, Cochrane library February 2001 to November 2010. A flow diagram is presented in Figure 1, relevant publications of neuropathic pain is filtered by Prisma algorithm. Among 1108 publications, 803 publications were excluded based on title and abstract. Remaining 305 publications were screened by article's abstract and randomised control trials with detailed information. In that 305 publications, 187 articles were excluded depending on the selection criteria. With the remaining 118 articles which met eligibility criteria were 
screened again based on the pain intensity outcome assessed by VAS scale (0-100). In 118 articles, only 5 randomised control trials of opioid agonist with outcome measure and data helpful for analysis were taken and analysed.

\section{Study characteristics}

Opioid studies comprised of various neuropathic painful conditions like phantom limb, chronic sciatica, diabetic neuropathy, post amputation pain and post herpetic neuralgia were treated with morphine and oxycodone (WHO step III opioids). As represented in the Table 1, five opioid studies for neuropathic pain conducted in less than 12 weeks duration were analysed. All the opioid studies were similar in study design of randomized control studies with crossover type (exception Zin 2010 were parallel). Comparator group of either placebo/standard treatment used in all the five trials. Primary outcome was proportion of participants reporting $50 \%$ of pain relief or better from baseline validated through visual analogue scale (0-100) in all the five trials. As represented in Table 2, In this analysis, total number of patients with neuropathic pain (treatment including opioid and placebo/standard treatment group) were 305 patients in five trials. Among 305 patients, the total events taken place in opioid group was 72 out 154 patients who were treated with opioids (WHO step III opioids) and 46 events out of 151 patients in placebo/standard treatment group. The number per treatment group ranges from 31 to 170 (median $50 \pm 5$ ). The overall point estimate of risk difference was 0.17 (95\% CI 0.02 to $0.33, \mathrm{p}=0.03)$ translating to number needed to treat (benefit) of 5.9 (3.0 to 50.0). As shown in the Figure 2, there is a significant difference in reducing spontaneous neuropathic pain $>50 \%$ relief between WHO step III (strong opioids morphine and oxycodone) and placebo/standard treatment in three of the five trials $(\mathrm{df}=4$, $\mathrm{p}=0.07)$. Test for overall effect $\mathrm{Z}=2.23(\mathrm{p}=0.026)$ in favour of opioids showing significant difference between opioid and placebo/standard treatment.

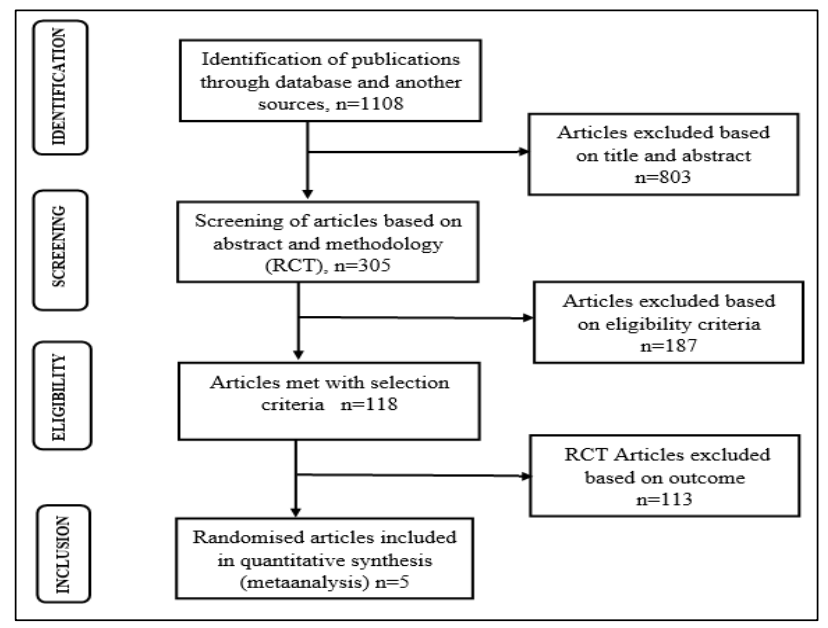

Figure 1: Selection of studies using Prisma algorithm.

Table 1: Characteristics of randomized trials included in the meta-analysis.

\begin{tabular}{|lllllll|}
\hline Trials & Diagnosis & $\begin{array}{l}\text { Study } \\
\text { design }\end{array}$ & $\begin{array}{l}\text { Sample } \\
\text { size }\end{array}$ & $\begin{array}{l}\text { Study } \\
\text { drugs }\end{array}$ & $\begin{array}{l}\text { Comparator } \\
\text { group }\end{array}$ & $\begin{array}{l}\text { Duration } \\
\text { (weeks) }\end{array}$ \\
\hline Huse, 2001 & Phantom limb & Crossover & 24 & Morphine 70-300 mg & Placebo & 4 \\
\hline Watson, 2003 & Diabetic neuropathy & Crossover & 68 & Oxycodone 10 mg CR & Placebo & 4 \\
\hline Khoromi, 2007 & Chronic sciatica & Crossover & 65 & Morphine 15-90 mg & $\begin{array}{l}\text { Nortriptyline } \\
25-100 \mathrm{mg}\end{array}$ & 5 \\
\hline Wu, 2008 & Post amputation pain & Crossover & 93 & Morphine 112 mg & $\begin{array}{l}\text { Mexiletine } \\
933 \mathrm{mg}\end{array}$ & 8 \\
\hline Zin, 2010 & Post herpetic neuralgia & Parallel & 55 & Oxycodone 10 mg & Placebo & 4 \\
\hline
\end{tabular}

Table 2: Comparison of efficacy of opioid versus placebo in RCTs included in meta-analysis.

\begin{tabular}{|lllll|}
\hline Study & Opioid & Control & Weight & Risk difference, CI \\
\hline Huse, 2001 & $5 / 12$ & $1 / 12$ & $14.1 \%$ & $0.33(0.01,0.65)$ \\
\hline Watson, 2003 & $21 / 34$ & $8 / 34$ & $21.3 \%$ & $0.38(0.17,0.60)$ \\
\hline Khoromi, 2007 & $8 / 32$ & $13 / 43$ & $23.3 \%$ & $0.10(-0.10,0.29)$ \\
\hline Wu, 2008 & $23 / 50$ & $13 / 43$ & $18.1 \%$ & $0.16(0.04,0.35)$ \\
\hline Zin, 2010 & $15 / 26$ & $19 / 29$ & $18.1 \%$ & $-0.08(-0.34,0.18)$ \\
\hline Total $(95 \% \mathrm{CI})$ & $72 / 154$ & $46 / 151$ & $100.0 \%$ & $0.17(0.02,0.33)$ \\
\hline
\end{tabular}

\section{DISCUSSION}

Our meta-analysis study was conducted to emphasis the analgesic efficacy of opioids (WHO step III-strong opioids) in related to other standard treatment/placebo in neuropathic pain. As represented in Table 2, all the results of 5 trials were pooled in to forest plot which were to display the estimated measure of effect size of each of 
these trials, to determine the mean difference in effect size between opioids and placebo, to demonstrate the heterogeneity among the five trials to know whether the same effect overlap well or not.

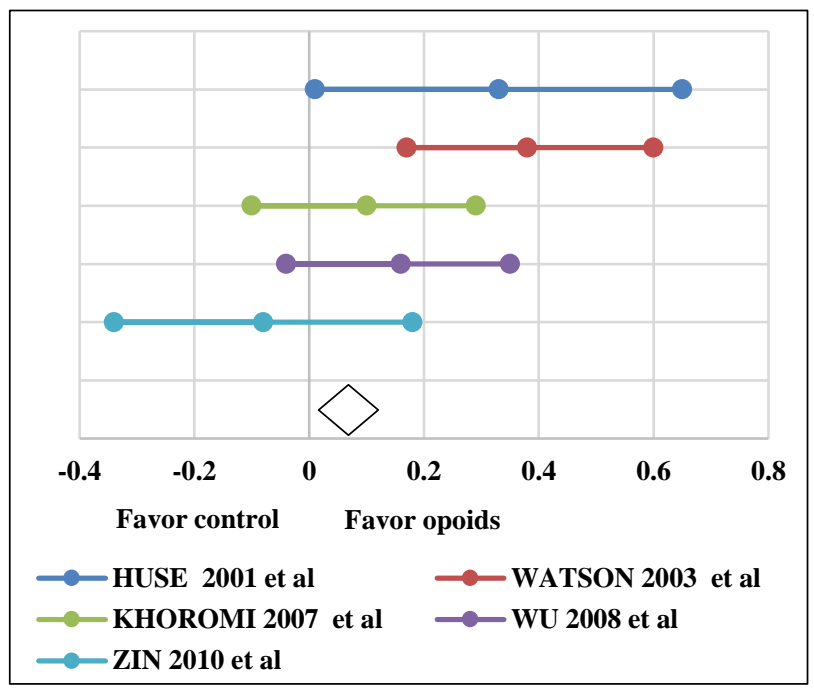

Figure 2: Efficacy of opioids and placebo/standard treatment in neuropathic pain and heterogeneity among five trials.

Author's results shown that three out of five trials have a point estimate (weight of the study) and horizontal line representing $95 \% \mathrm{CI}$ in favour of opioids. The heterogeneity is indicated by $\mathrm{I} 2$ test $=55 \%$, indicates some dissimilarity among five trials. The overall point estimate of risk difference was 0.17 (95\% CI 0.02 to $0.33, \mathrm{P}=0.03$ ) translating to number needed to treat of 5.9 (3.0 to 50.0) indicating strong opioids had promising benefit over placebo/standard treatment in causing pain relief. Thus, author found that overall analgesic efficacy of strong opioids (morphine, oxycodone) is significantly different from placebo/standard treatment in treating neuropathic painful conditions such as phantom limb, diabetic neuropathy and post amputation pain. Present results contradicted the other meta-analysis results such as Chou $\mathrm{R}$ et al, in which they concluded that the strong efficacy opioids were not significantly different from any other first line treatment/ placebo. ${ }^{21,22}$ In this study, the role of opioids is found to be non-beneficial in chronic sciatica and post herpetic neuralgia. This result extends the similarity in opinion of opioids to other studies conducted by Chaparro LE et al, and Mcnicol ED et al, which also emphasizes that the net benefit of opioids relative to other standard treatment in neuropathic pain had smaller value than the efficacy difference between active standard treatment and its control. ${ }^{23,24}$

Methodologically, adequate RCTs are necessary for causal inference and prevent over emphasis of selected (positive) results. Present study analysis was completely based on high quality RCTs in which all the trials chosen depending on following consideration.
- Neuropathic painful conditions were chosen according to previous clinical or experimental observations.

- Patients were selected in such a way to minimize variance and to maximize treatment outcomes.

- Neither of the author leave the positive/negative results unpublished.

Thus, present study conclusions were obtained from possible/optimized condition to prevent risk of bias across studies.

Even though strong opioids have marked efficacy over other treatment in causing pain relief, opioids did not demonstrate improvement in functional outcome, as measured by validated questionnaires. This brings the concern that improvement in pain relief is not accompanied by improvement in quality of life/activities of daily living. Combined clinical evaluation of pain relief, physical and emotional functioning and adverse effects will reflect the effect size as clinically relevant and reveals individual improvement of patients.

Limitations of this study were RCTs analyzed have smaller size and duration of trials less than 12 weeks which may prone for impending bias. Risk of bias was not assessed using funnel plot for these trials due to its smaller size. Since, smaller size trials leads to false positive results.

\section{CONCLUSION}

In this meta-analysis study, opioid agonist efficacy trials shown consistent analgesic efficacy and benefit over placebo/controls in reducing neuropathic pain. Since, these randomized trials have smaller size, they are liable to bias. Opioids have greater efficacy in pain relief but functional outcome, quality of life, safety and patient's adherence needed to be evaluated in future studies.

\section{ACKNOWLEDGEMENTS}

Authors would like to thank Central Library Facility and Faculty of Department of Pharmacology, Government Stanley Medical College, Tamil Nadu, India for their support during study.

Funding: No funding sources

Conflict of interest: None declared

Ethical approval: The study was approved by the Institutional Ethics Committee of Govt. Stanley Medical College, Tamil Nadu, India

\section{REFERENCES}

1. Christoph S, Andress K. Anesthesia and treatment of chronic pain. Section V-Adult sub-speciality management. In : Miller RD, Eriksson LI , Fleisher LA, Wiener-kronish JP, Young WL, eds. Miller's Anesthesia, 7th ed. Philadelphia: Churchill Livingstone. Elsevier; 2010:1977. 
2. Treede RD, Jensen TS, Campbell JN, Cruccu G, Dostrovsky JO, Griffin JW, et al. Neuropathic pain: redefinition and a grading system for clinical and research purposes. Neurology. 2008;70:1630-5.

3. Classification of chronic pain. descriptions of chronic pain syndromes and definitions of pain terms. prepared by the international association for the study of pain, subcommittee on taxonomy. Pain Suppl. 1986;3(S1):226.

4. Willis WD, Westlund KN. Neuroanatomy of the pain system and of the pathways that modulate pain. J Clin Neurophysiol. 1997;14(1):2-31.

5. Welch SP, Martin BR. Opioid and nonopioid analgesics. In: Craig CR, Stitzel RE, eds. Modern Pharmacology with Clinical Applications. 6th ed. Philadelphia, USA: Lippincott William Wilkins; 2004: 310-329.

6. Laxmaiah Manchikanti M, Bert Fellows M, Hary Ailinani M. Therapeutic use, abuse, and nonmedical use of opioids: a ten-year perspective. Pain Physician. 2010;13:401-35.

7. Eisenberg E, McNicol ED, Carr DB. Efficacy and safety of opioid agonists in the treatment of neuropathic pain of nonmalignant origin: systematic review and meta-analysis of randomized controlled trials. JAMA. 2005;293(24):3043-52.

8. Trescot AM, Helm S, Hansen H, Benyamin R, Glaser SE, Adlaka R, et al. Opioids in the management of chronic non-cancer pain: an update of American Society of the Interventional Pain Physician's (ASIPP) Guidelines. Pain Physician. 2008;11(2 Suppl):S5-62.

9. Chou R, Turner JA, Devine EB, Hansen RN, Sullivan SD, Blazina I, et al. The effectiveness and risks of long-term opioid therapy for chronic pain: a systematic review for a National Institutes of Health Pathways to Prevention Workshop. Ann Internal Med. 2015;162(4):276-86.

10. Alford DP. Opioid prescribing for chronic painachieving the right balance through education. New Eng J Med. 2016;374(4):301-3.

11. Moher D, Schulz KF, Simera I, Altman DG. Guidance for developers of health research reporting guidelines. PLoS Med. 2010;7(2):e1000217.

12. Glasziou P, Vandenbroucke J, Chalmers I. Assessing the quality of research. BMJ. 2004;328(7430):39-41.

13. Cook DJ, Mulrow CD, Haynes RB. Systematic reviews: synthesis of best evidence for clinical decisions. Ann Internal Med. 1997;126(5):376-80.

14. Clarke M. Cochrane Collaboration and systematic reviews. Brit J Surg. 2007;94(4):391-2.
15. Furlan AD, Sandoval JA, Mailis-Gagnon A, Tunks E. Opioids for chronic noncancer pain: a meta-analysis of effectiveness and side effects. CMAJ. 2006;174:158994.

16. Huse E, Larbig W, Flor H, Birbaumer N. The effect of opioids on phantom limb pain and cortical reorganization. Pain. 2001;90(1-2):47-55.

17. Watson CP, Moulin D, Watt-Watson J, Gordon A, Eisenhoffer J. Controlled-release oxycodone relieves neuropathic pain: a randomized controlled trial in painful diabetic neuropathy. Pain. 2003;105(1-2):718.

18. Khoromi S, Cui L, Nackers L, Max MB. Morphine, nortriptyline and their combination vs. placebo in patients with chronic lumbar root pain. Pain. 2007; 130(1-2):66-75.

19. Wu CL, Agarwal S, Tella PK, Klick B, Clark MR, Haythornthwaite JA, et al. Morphine versus mexiletine for treatment of postamputation paina randomized, placebo-controlled, crossover trial. Anesthesiol J Am Soc Anesthesiol. 2008;109(2):28996.

20. Zin CS, Nissen LM, O'Callaghan JP, Duffull SB, Smith MT, Moore BJ. A randomized, controlled trial of oxycodone versus placebo in patients with postherpetic neuralgia and painful diabetic neuropathy treated with pregabalin. J Pain. 2010;11:462-71.

21. Chou R, Ballantyne JC, Fanciullo GJ, Fine PG, Miaskowski C. Research gaps on use of opioids for chronic noncancer pain: findings from a review of the evidence for an American Pain Society and American Academy of Pain Medicine clinical practice guideline. J Pain. 2009;10:147-59.

22. Chou R, Fanciullo GJ, Fine PG, Adler JA, Ballantyne JC, Davies P, et al. Clinical guidelines for the use of chronic opioid therapy in chronic noncancer pain. The J Pain. 2009;10(2):113-30.

23. Chaparro LE, Furlan AD, Deshpande A, MailisGagnon A, Atlas S, Turk DC. Opioids compared to placebo or other treatments for chronic low-back pain. Cochrane Database Sys Rev. 2013;(8).

24. McNicol ED, Midbari A, Eisenberg E. Opioids for neuropathic pain. Cochrane Database Sys Rev. 2013;(8):CD006146.

Cite this article as: Preethi A, Kulandaiammal MA. A meta-analysis of analgesic efficacy of opioids in the treatment of neuropathic pain. Int J Basic Clin Pharmacol 2019;8:752-6. 